Gazi University
Journal of Science
http://dergipark.gov.tr/gujs

\title{
Investigation of Hydrogen Production from Bio-Oil Substances Using Aspen Plus
}

\author{
Mesut BEKIROGULLARI* (iD), Mustafa KAYA \\ Siirt University, Faculty of Engineering, Department of Chemical Engineering, Siirt
}

\author{
Highlights \\ - The use of bio-oil compounds to produce hydrogen was undertaken. \\ - Production of hydrogen from five different bio-oil feedstocks were assessed. \\ - The compounds that contains less C-C bounds was able to achieve $100 \%$ conversion. \\ - Such simulation approaches can be exploited for robust design and optimization.
}

\begin{tabular}{l} 
Article Info \\
\hline \\
Received: 08/04/2019 \\
Accepted: 07/10/2019 \\
Keywords \\
\hline Aspen Plus \\
Bio-Oil Compounds \\
Hydrogen Energy \\
Steam Reforming \\
Reactor Temperature
\end{tabular}

1. INTRODUCTION

The worldwide growing energy demand and concerns about climate change have increased the interest towards alternative energy sources that are sustainable, economical and also environmentally friendly [1, 2]. In this regard, hydrogen $\left(\mathrm{H}_{2}\right)$ production has drawn great attention in the field of energy due to its potential to substitute fossil fuels both in transportation and electricity generation with fuel cell systems [36]. Additionally, hydrogen is the most common element in the world and it's an essential substance in petrochemical industry for clean fuel production. Currently, hydrogen production is performed through catalytic steam reforming of fossil-fuel derived compounds such as coal, alcohols, light hydrocarbons and naphtha followed by water gas shift $[7,8]$. However, use of fossil-fuel derived compounds for hydrogen production fails to address carbon dioxide emission that is being released while the reforming processes. The shortage of fossil-fuels derived compounds in the near future is also a great concern which can cause serious energy problems. Therefore, in order to realise economic viability of hydrogen production, much attention has been given to use of biomass energy resources due to its outstanding characteristics such as being available, renewable and carbon neutral.

Considerable approaches including physical and thermo-chemical pathways have been established to convert biomass into hydrogen, mainly involving pyrolysis and gasification of biomass resources at a range 
of temperature and pressure [8]. Among the developed procedures, the steam reforming process preceded by the flash pyrolysis is the most promising biomass to hydrogen production strategy [9].

Several studies have been carried out to investigate hydrogen production through steam reforming process with the aid of ASPEN PLUS simulation software. Unlu et al. (2019) have discovered the effect of reactor type, temperature, pressure, feed ratio and reactor parameters on the conversion of glycerol by steam reforming process [10]. On the other hand, Giwa et al. (2013) undertaken a case study to analyse the effect of reactor temperature on the conversion of glycerol for the production of hydrogen through steam reforming process [11].

Use of bio-oil for hydrogen production offers several advantages compared to other fossil fuel derived compounds and hydrocarbons $[9,12]$. For the sake of storage and transportation these types of resources are favourable in liquid form at room temperature. Additionally, bio-oils provide high $\mathrm{H} / \mathrm{C}$ ratio and absence of $\mathrm{C}-\mathrm{C}$ bounds. Thus, steam reforming of single bio-oil substances in the aqueous form has gain great research interest. Prior to implementing this technology, the correctness and efficiency of such processes needs to be determined. In this sense, Aspen Plus simulator is a powerful tool to obtain the relation between input and output of the processes, feedstocks conversions and output mass and molar flow rates [11].

With this background, the objective of this work was to carry out a systematic and detailed comparison of different bio-oil components for hydrogen production through steam reforming process by applying Aspen Plus. The effect of temperature on the conversion of selected components, ethylene glycol, acetic acid, ethyl acetate, acetone, m-xylene, the main components that can be found in bio-oil, were studied. Mass and molar flow rates and fractions of hydrogen derived from different bio-oil compounds were also studied.

\section{MATERIALS AND METHODS}

The process flowsheet shown in Figure 1 was simulated in Aspen Plus (AspenTech, Burlington, MA), a highly suggested and powerful tool to obtain efficient data prior to experimentation and implementation of the technology. As can be seen in the simulation flowsheet, the process contains two feed streams (bio-oil components and water) that were fed into a mixer prior to sending to the reactor. Although the concentration for each of the bio-oil components can vary depending on the bio-oil composition, the concentrations for each of the tested bio-oil compounds were kept constant for a better comparison of conversion ratios. For all bio-oil components the flow rate were set to $0.065 \mathrm{kmol} / \mathrm{h}$ and for water the flow rate was set based on the reaction coefficients given in Table 1 . The pressure and temperature of the bio-oil components and water were set to $1 \mathrm{~atm}$ and $30^{\circ} \mathrm{C}$, respectively. The mixer pressure was also set to $1 \mathrm{~atm}$ as it was only applied to blend the two liquid streams. The stream that was leaving to mixer was then fed to a heater where the mixed stream was brought to reaction temperature before entering to the reactor. Finally, the stream that was leaving the heater was fed into equilibrium reactor. The REquilibrium reactor uses the stoichiometry of the reaction and the chemical balance between the reactions to determine the concentration and the phase balance between products [13]. The thermal operation mode of reactor was selected as isotherm. The chosen starting temperature for the equilibrium reactor was $30^{\circ} \mathrm{C}$ and it was varied to up to $1100{ }^{\circ} \mathrm{C}$ to investigate conversion ratio of selected components, acetic acid, ethylene glycol, ethyl acetate, acetone and $\mathrm{m}$-xylene and also the qualities, mass and molar flow rates of produced hydrogen. 


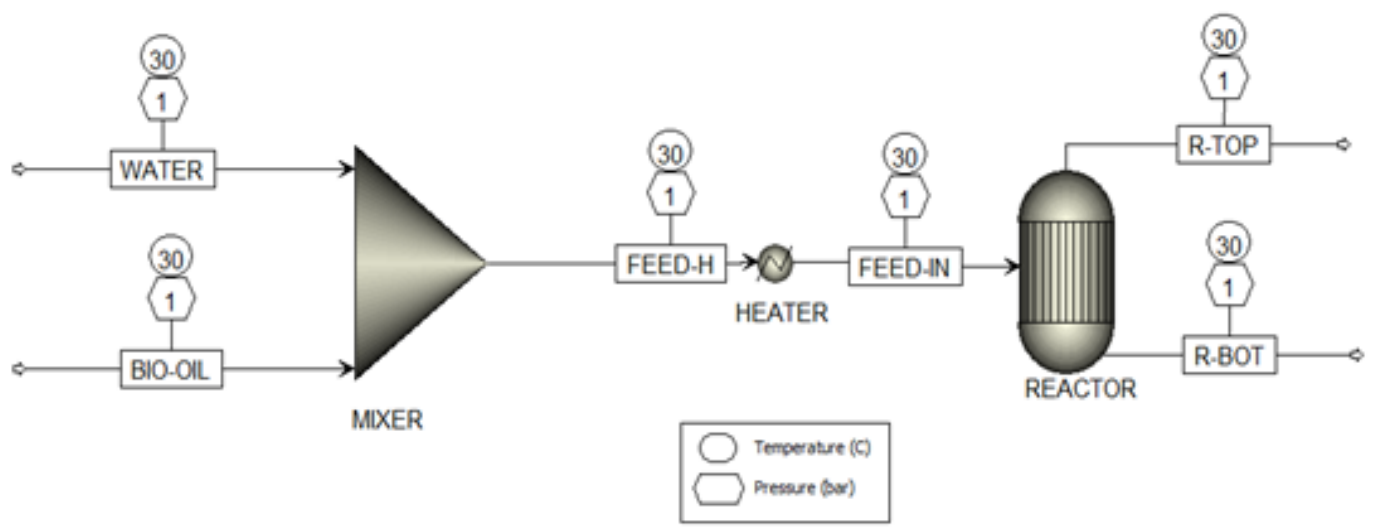

Figure 1. Aspen Plus simulation flowsheet of hydrogen production from bio-oils through the steam reforming process

The steam reforming process reactions were considered as equilibrium reactions taking into account the overall reactions of each of the five bio-oil compounds. Table 1 outline the stoichiometry of the chemical reactions of the five bio-oil compounds that were involved in steam reforming process.

Table 1. The stoichiometry for the compounds involving in steam reforming process

\begin{tabular}{|c|c|c|}
\hline Reaction & Reaction No. & $\Delta H_{298}^{o}(\mathrm{~kJ} / \mathrm{mol})$ \\
\hline $\mathrm{CH}_{3} \mathrm{COOH}+2 \mathrm{H}_{2} \mathrm{O} \rightarrow 4 \mathrm{H}_{2}+2 \mathrm{CO}_{2}$ & $(1)$ & 131.4 \\
\hline $\mathrm{CH}_{2} \mathrm{OHCH}_{2} \mathrm{OH}+2 \mathrm{H}_{2} \mathrm{O} \rightarrow 5 \mathrm{H}_{2}+2 \mathrm{CO}_{2}$ & $(2)$ & 86.2 \\
\hline $\mathrm{CH}_{3} \mathrm{COOCH}_{2} \mathrm{CH}_{3}+6 \mathrm{H}_{2} \mathrm{O} \rightarrow 10 \mathrm{H}_{2}+4 \mathrm{CO}_{2}$ & $(3)$ & 320.1 \\
\hline $\mathrm{CH}_{3} \mathrm{COCH}_{3}+5 \mathrm{H}_{2} \mathrm{O} \rightarrow 8 \mathrm{H}_{2}+3 \mathrm{CO}_{2}$ & $(4)$ & 246.3 \\
\hline $\mathrm{C}_{8} \mathrm{H}_{10}+16 \mathrm{H}_{2} \mathrm{O} \rightarrow 21 \mathrm{H}_{2}+8 \mathrm{CO}_{2}$ & $(5)$ & 738.4 \\
\hline
\end{tabular}

Here, we present a comprehensive investigation of use of bio-oil compounds to produce hydrogen with the aid of Aspen Plus. By using the stoichiometry of five bio-oil compounds given above and the simulation developed in Aspen Plus, the conversion ratios at different temperatures were investigated and the mass and molar flow rates of hydrogen production by each of the feedstock were figured against the varied temperature to realise the behaviour of bio-oil compounds variations graphically.

\section{RESULTS AND DISCUSSION}

A simulation study was undertaken to quantify the effect of varying reactor temperature on the conversion rate of bio-oil feedstocks and qualities and hydrogen production rates with the aid of Aspen Plus. The process comprises a complex reaction system due to several pathways for the conversion of bio-oil feedstocks and in-situ reactions between the primary products such as carbon monoxide, water and methanol. Therefore, in order to obtain the highest hydrogen yield in the steam reforming process; the reactor temperature needs to be above $100{ }^{\circ} \mathrm{C}$. However; in the current work the starting temperature was chosen to be $30{ }^{\circ} \mathrm{C}$ to in order to draw an appropriate conclusion of the steam reforming process. Thus, the reactor temperature was varied from $30{ }^{\circ} \mathrm{C}$ to $1100{ }^{\circ} \mathrm{C}$. Conversion of the bio-oil feedstock with respect to temperature was first analysed. Afterwards, the mass and mole fractions of hydrogen attained from the steam reforming process were explored. For further analysis, conversions of the bio-oil feedstock versus reactor temperature were plotted in Figure 2. 


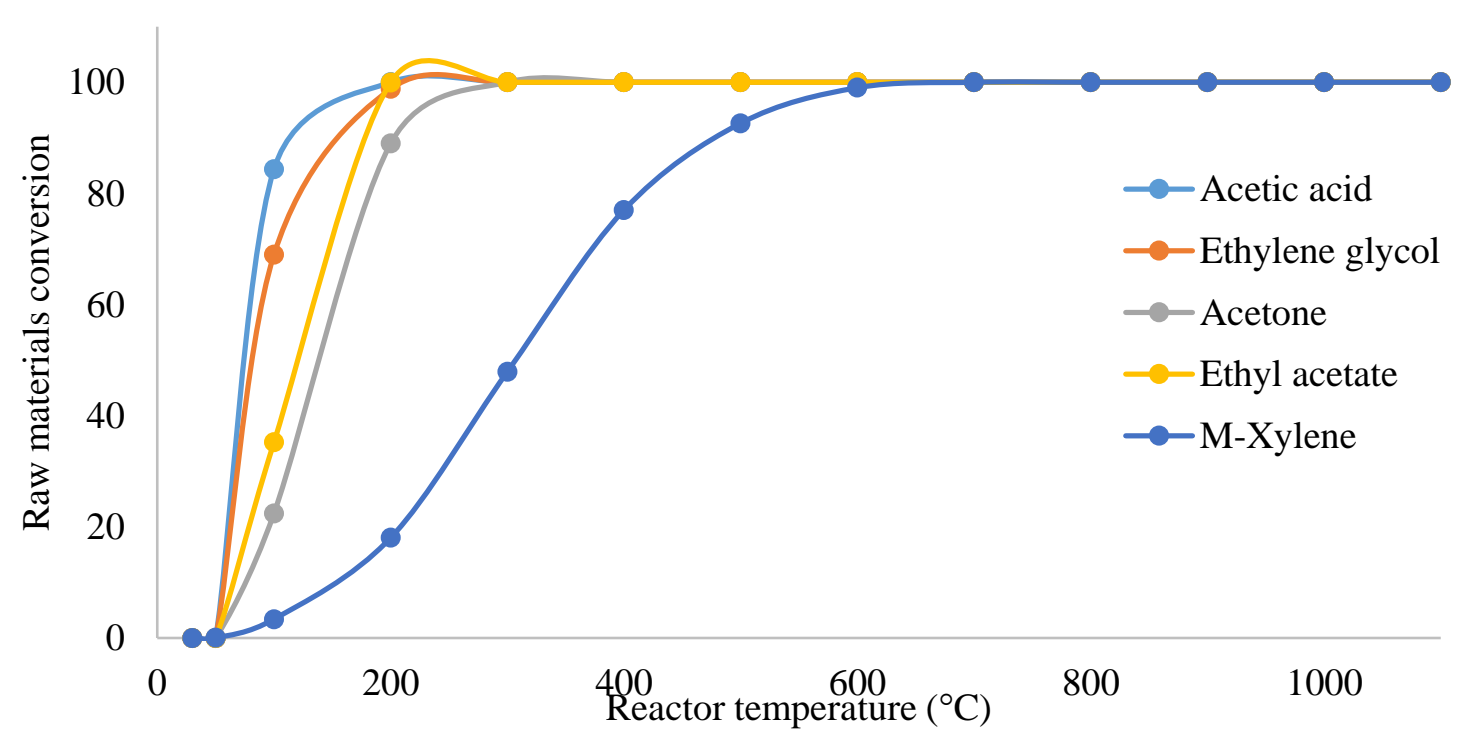

Figure 2. Conversion of bio-oil feedstocks through steam reforming process for the hydrogen production with respect to different reactor temperatures

The conversion ratio-temperature profiles reveal that the profiles could be analysed in two different groups: the light feedstocks (acetic acid, ethylene glycol, ethyl acetate and acetone) and heavy feedstocks (mxylene). As can be seen from the figure that the light feedstock can completely be converted at lower reactor temperatures $\left(200-300^{\circ} \mathrm{C}\right)$ while heavy feedstocks requires higher reactor temperature (above 600 $\left.{ }^{\circ} \mathrm{C}\right)$ to achieve $100 \%$ conversion. Temperature over $800{ }^{\circ} \mathrm{C}$ did not improve the bio-oil conversions to $\mathrm{H}_{2}$ for all of the tested components. The ascending reactor temperature for the light feedstocks to achieve $100 \%$ conversion was the following: acetic acid, ethylene glycol, ethyl acetate and acetone. This was mainly due to short carbon chains in the feedstocks and the reaction stochiometries [10]. Therefore, the number of C$\mathrm{C}$ bounds that needs to be cracked down was less in the reforming process. Consequently, the reactor temperature was lower for reforming of light feedstocks. Conversely, the heavy feedstocks require higher reactor temperature to achieve $100 \%$ conversion as they contain more $\mathrm{C}-\mathrm{C}$ bounds. The reactor temperature for the full conversion of heavy feedstock (m-xylene) was higher compare to light feedstocks. The reactor temperature findings were in good agreement with available literature [9].

The mole fraction of hydrogen production from bio-oil feedstocks versus temperature were summarized in Figure 3. As the Figure 3 indicates the highest mole fraction of hydrogen (0.7) in the steam reforming process was obtained from heavy feedstock (m-xylene) at relatively higher temperatures $\left(500-600{ }^{\circ} \mathrm{C}\right)$. The hydrogen mole fraction for the light feedstocks were relatively lower compare to heavy feedstock and it ascends in the following order: Acetic acid < ethylene glycol < acetone < ethyl acetate. The mole fraction of hydrogen became stable at lower temperatures for the light components and vice versa. 


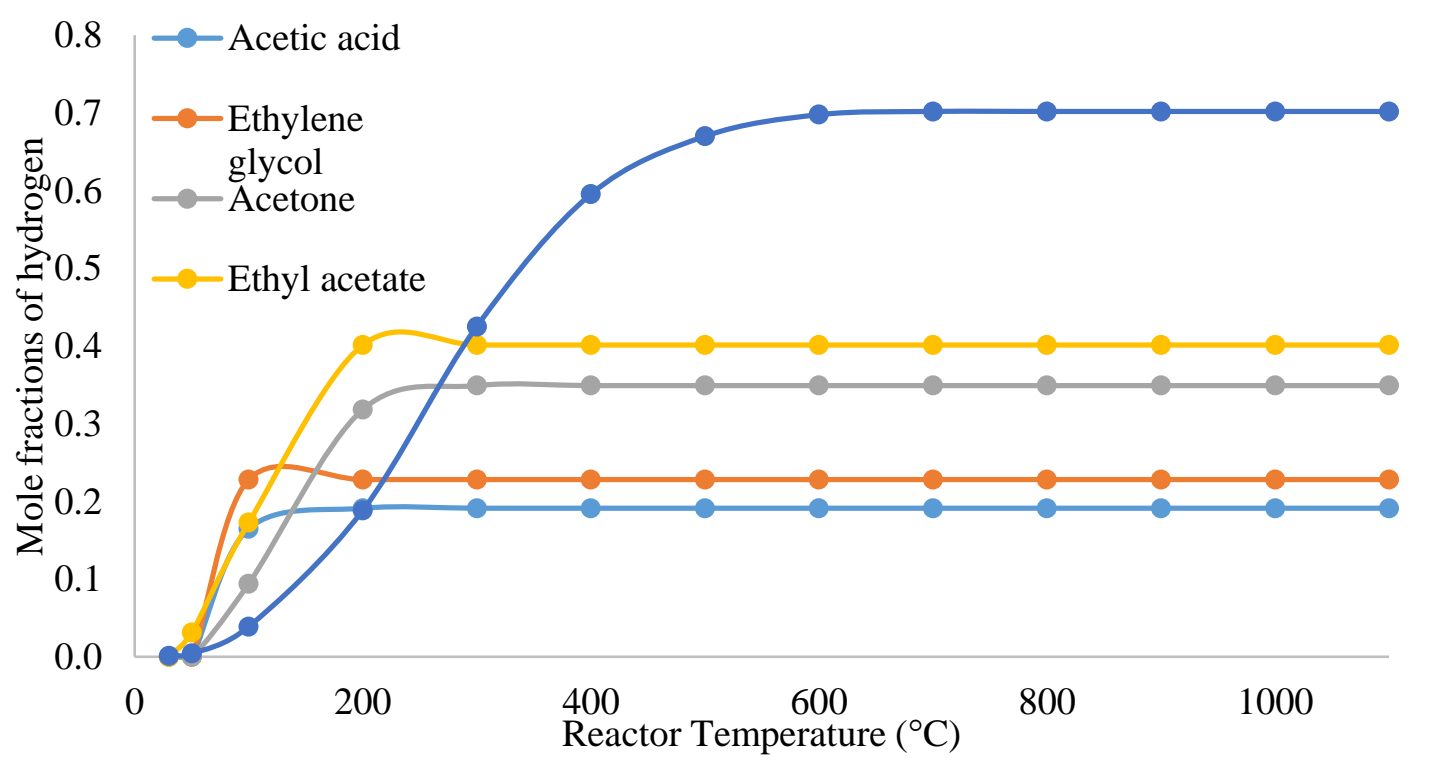

Figure 3. Mole fraction of hydrogen obtained in the steam reforming process of bio-oil feedstock at different reactor temperatures

The mass flow rates of hydrogen produced in steam reforming process of bio-oil compounds were also investigated in this study and the relevant data was plotted in Figure 4. The obtained results were similar to the one given for molar fraction of hydrogen. Here, it can be seen that the amount of hydrogen produced from m-xylene $(2.75 \mathrm{~kg} / \mathrm{h})$ was about 2-6 times higher compare light components. Again, in steam reforming heavy bio-oil feedstock requires higher temperature (above $600{ }^{\circ} \mathrm{C}$ ) for the full conversion compare to light feedstocks [9]. At relatively lower temperatures $\left(0-300{ }^{\circ} \mathrm{C}\right)$, the mass flow rate of hydrogen was 1-3 times higher relative to $\mathrm{m}$-xylene with the ethyl acetate to have highest mass flow of hydrogen.

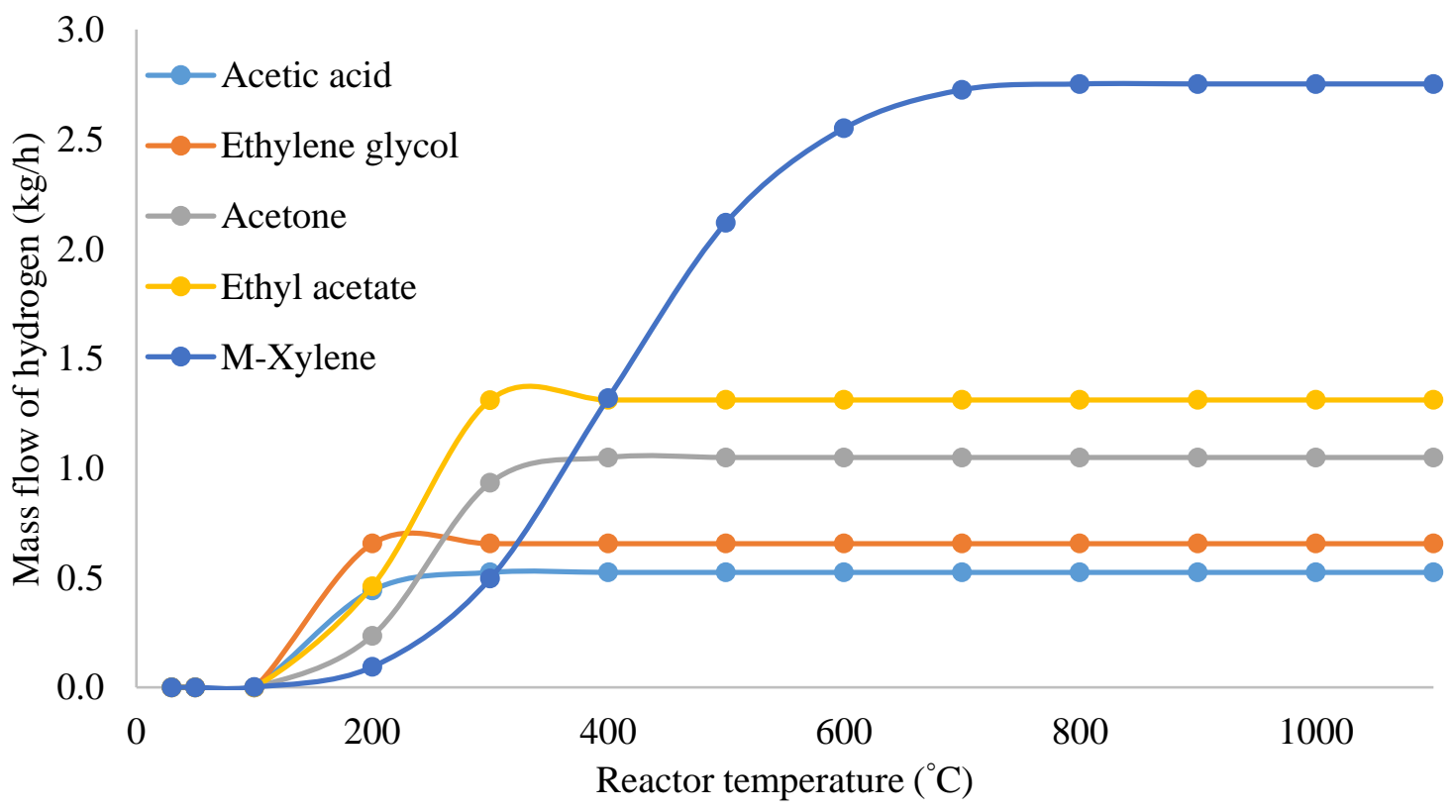

Figure 4. Mass flow rate of hydrogen obtained in the steam reforming process of bio-oil feedstock at different reactor temperatures 
Mass and volume fraction of hydrogen were also examined in this study and similar observations were seen same as mole fraction and mass flow of hydrogen. The findings suggest that the feedstocks that contains less C-C bounds (light feedstocks) can achieve 100\% conversion at relatively lower temperatures and vice versa. In converse, higher mass and mole fraction of hydrogen can only be obtained from heavy feedstocks. The detailed composition of the inlet and outlet stream at $600{ }^{\circ} \mathrm{C}$ for each of the bio-oil component is provided in Table 2. As the table outlines, the stream that is leaving the reactor mainly consist of $\mathrm{H}_{2} \mathrm{O}$ and $\mathrm{CO}_{2}$ as all the reactions took place with almost $100 \%$ conversion.

Table 2. The inlet and outlet stream composition at $600{ }^{\circ} \mathrm{C}$ for each of the bio-oil component

\begin{tabular}{|c|c|c|c|c|c|}
\hline \multicolumn{3}{|c|}{ Case study 1: Acetic acid } & \multicolumn{3}{|c|}{ Case study 2: Ethylene glycol } \\
\hline Mole flows (kmol/hr) & Inlet & Outlet & Mole flows (kmol/hr) & Inlet & Outlet \\
\hline Total mole flow & 1.165 & 1.36 & Total mole flow & 1.165 & 1.425 \\
\hline Water & 1.1 & 0.97 & Water & 1.1 & 0.97 \\
\hline Carbon dioxide & 0 & 0.13 & Carbon dioxide & 0 & 0.13 \\
\hline Hydrogen & 0 & 0.26 & Hydrogen & 0 & 0.325 \\
\hline Acetic Acid & 0.065 & $1.30 \mathrm{E}-13$ & Ethylene glycol & 0.065 & $3.00 \mathrm{E}-22$ \\
\hline \multicolumn{3}{|l|}{ Case study 3: Acetone } & \multicolumn{3}{|c|}{ Case study 4: Ethylene acetate } \\
\hline Mole flows (kmol/hr) & Inlet & Outlet & Mole fFlows (kmol/hr) & Inlet & Outlet \\
\hline Total mole flow & 1.165 & 1.49 & Total mole flow & 1.165 & 1.62 \\
\hline Water & 1.1 & 0.775 & Water & 1.1 & 0.71 \\
\hline Carbon dioxide & 0 & 0.195 & Carbon dioxide & 0 & 0.26 \\
\hline Hydrogen & 0 & 0.52 & Hydrogen & 0 & 0.65 \\
\hline Acetone & 0.065 & $5.00 \mathrm{E}-16$ & Ethylene acetate & 0.065 & $1.70 \mathrm{E}-23$ \\
\hline \multicolumn{3}{|c|}{ Case study 5: M-Xylene } & & & \\
\hline Mole flows (kmol/hr) & Inlet & Outlet & & & \\
\hline Total mole flow & 1.165 & 1.937 & & & \\
\hline Water & 1.1 & 0.07 & & & \\
\hline Carbon dioxide & 0 & 0.515 & & & \\
\hline Hydrogen & 0 & 1.352 & & & \\
\hline M-Xylene & 0.065 & 0.0006 & & & \\
\hline
\end{tabular}

\section{CONCLUSIONS}

An investigation of the use of bio-oil compounds to produce hydrogen through steam reforming process was undertaken with the use of Aspen Plus. Production of hydrogen from five different bio-oil feedstocks (acetic acid, ethylene glycol, acetone, ethyl acetate and m-xylene) were assessed with respect different reactor temperature. It was found that the compounds that contains less $\mathrm{C}-\mathrm{C}$ bounds (light feedstocks) can achieve $100 \%$ conversion at relatively moderate temperatures. Acetic acid, ethylene glycol, acetone and ethyl acetate could efficiently be reformed to hydrogen below $300{ }^{\circ} \mathrm{C}$, while much higher reactor temperature was needed to convert $\mathrm{m}$-xylene. Although higher reactor temperatures are required for the full conversion, higher mole and mass fraction of hydrogen can only be obtained from heavy feedstock. The results obtained with respect to reactor temperature variations are in good agreement with the data presented 
in literature. This illustrates the usefulness of carefully constructed simulations of the steam reforming process. Such successfully developed simulations can be exploited for the robust design, control and scaleup of steam reforming process. Such simulations can also help to reduce experimentation cost and time.

\section{CONFLICTS OF INTEREST}

No conflict of interest was declared by the authors.

\section{REFERENCES}

[1] Brennan L., Owende P., "Biofuels from microalgae-a review of technologies for production, processing, and extractions of biofuels and co-products," Renewable and Sustainable Energy Reviews, 14: 557-577, (2010).

[2] Hosseini S. E., Wahid M. A., "Hydrogen production from renewable and sustainable energy resources: promising green energy carrier for clean development," Renewable and Sustainable Energy Reviews, 57: 850-866, (2016).

[3] Armor J., "Catalysis and the hydrogen economy," Catalysis letters, 101: 131-135, 2005.

[4] Bekiroğullari M., Kaya M., Saka C., "Highly efficient Co-B catalysts with Chlorella Vulgaris microalgal strain modified using hydrochloric acid as a new support material for hydrogen production from methanolysis of sodium borohydride," International Journal of Hydrogen Energy, 44: 7262-7275, (2019).

[5] Brack P., Dann S. E., Wijayantha K. U., "Heterogeneous and homogenous catalysts for hydrogen generation by hydrolysis of aqueous sodium borohydride $\left(\mathrm{NaBH}_{4}\right)$ solutions," Energy Science \& Engineering, 3, 174-188, (2015).

[6] Rivarolo M., Improta O., Magistri L., Panizza M., Barbucci A., "Thermo-economic analysis of a hydrogen production system by sodium borohydride $\left(\mathrm{NaBH}_{4}\right)$," International Journal of Hydrogen Energy, 43: 1606-1614, (2018).

[7] Dutta S., "A review on production, storage of hydrogen and its utilization as an energy resource," Journal of Industrial and Engineering Chemistry, 20: 1148-1156, (2014).

[8] Nikolaidis P., Poullikkas A., "A comparative overview of hydrogen production processes," Renewable and Sustainable Energy Reviews, 67: 597-611, (2017).

[9] Hu X., Lu G., "Investigation of the steam reforming of a series of model compounds derived from biooil for hydrogen production," Applied Catalysis B: Environmental, 88: 376-385, (2009).

[10] Unlu D., Hilmioglu N. D., "Application of aspen plus to renewable hydrogen production from glycerol by steam reforming," International Journal of Hydrogen Energy, 45(5): 3509-3515, (2019).

[11] Giwa A. G. a. O., "Application of Aspen Plus to Hydrogen Production from Alcohols by Steam Reforming: Effects of Reactor Temperature", International Journal of Engineering Research \& Technology, 2: 648-657, (2013).

[12] Usman M. R., Cresswell D. L., "Options for on-board use of hydrogen based on the methylcyclohexane-toluene-hydrogen system," International Journal of Green Energy, 10: 177-189, (2013).

[13] Ralph S., "Teach yourself the basics of Aspen Plus”. Hoboken, NJ, USA: Wiley, (2011). 